\title{
PENGARUH PRICE EARNING RATIO, DEBT TO EQUITY RATIO DAN RETURN ON EQUITY TERHADAP HARGA SAHAM PT. MANDOM INDONES, Tbk
}

\author{
Aniyah Amalia Saputri 1) \\ 1) Mahasiswa Program Studi Manajemen FE UNKRIS \\ Herry Winarto ${ }^{2)}$ \\ 2) Dosen Program Studi Manajemen FE UNKRIS \\ Alamat : Kampus UNKRIS, Jatiwaringin Jakarta Timur \\ Email : herry winarto45@Yahoo.Com
}

\begin{abstract}
This type of research uses quantitative research. The data sources used in the study are secondary data. The data analysis method used is hypothesis testing namely $f$ test and t test. The results of this study indicate that Price Earning Ratio, Debt To Equity Ratio, Return On Equity simultaneously have a significant effect on stock prices. Partially Price Earning Ratio, and Return On Equity do not have a significant effect, while Debt To Equity Ratio partially has a significant effect on the stock price of PT Mandom Indonesia Tbk. To get the data, researchers used the website of PT Mandom Indonesia Tbk, and the Indonesia Stock Exchange (IDX). By conducting financial data research during the 2013-2017 period which was analyzed using SPSS 24.0
\end{abstract}

Keywords: Price earning ratio, debt to equity ratio, return on equity and stock price

\section{PENDAHULUAN}

Pada pertumbuhan ekonomi yang makin meningkat, sekelompok orang mulai melakukan berbagai macam cara menginvestasikan hartanya untuk memperoleh keuntungan dimasa mendatang. Salah satunya dengan cara menginvestasikan harta atau uangnya melalui pasar modal, karena berinvestasi di pasar modal adalah mudah, sederhana dan tidak mahal (Nicky, 2017). Warren Buffet adalah salah satu orang terkaya di dunia yang sukses berinvestasi melalui pasar modal. Sekelompok orang pun mulai mencoba mengikuti jejak langkah kesuksesannya dengan melakukan riset dan pengamatan atas saham-saham apa yang akan menghasilkan keuntungan capital gain yang tinggi. Didalam aktifitas pasar modal, para pemodal (investor) dapat memilih jenis transaksi yang akan dijual/dibeli dalam jangka pendek, jangka menengah dan jangka panjang. Hariyani dan Serfianto (2010) mengatakan investor harus tetap berhati-hati meskipun investasi dalam bentuk saham menjanjikan keuntungan lebih besar. Investasi di pasar modal tidak dijamin oleh pemerintah sehingga investor sewaktu-waktu dapat merugi bahkan rugi total karena sahamnya tidak bernilai sama sekali.

Sebelum menanamkan investasinya, para investor perlu menilai kinerja perusahaan yang baik melalui laporan keuangan dengan tujuan untuk mengetahui kinerja keuangan perusahaan dari waktu ke waktu. Analisis yang dipakai untuk mendeteksi kesehatan suatu perusahaan dan problem-problem yang sedang dihadapinya adalah melalui analisis rasio 
(Kuswadi, 2008). Analisis rasio ini menggunakan informasi yang dihasilkan dari laporan keuangan perusahaan (Kho Sin \& Fransiska, 2017).

Analisis terhadap laporan keuangan perusahaan menurut Hanafi (2009) bertujuan untuk mengukur kinerja keuangan yaitu tingkat keuntungan, tingkat kesehatan dan tingkat resiko suatu perusahaan dengan menghitung data rasio-rasio keuangan perusahaan. Christina (2010) mengatakan perolehan modal perusahaan akan meningkat apabila perusahaan memiliki reputasi nama yang baik akan terlihat dari laporan keuangannya. Perusahaan yang memiliki reputasi yang baik akan menarik minat para investor untuk menanamkan investasinya di perusahaan tersebut. Pertimbangan harga saham sangat penting untuk investor karena menggambarkan nilai perusahaan. Semakin tinggi harga saham maka semakin tinggi juga nilai perusahaan. Sebaliknya apabila harga saham rendah maka nilai perusahaan akan semakin rendah juga.

Dalam menentukan pengambilan keputusan investasi, investor perlu mempertimbangkan secara matang perusahaan mana yang akan memberikan keuntungan yang maksimal melalui perhitungan atau analisis yang rasional. Sesuai faktor-faktor yang mempengaruhinya, analisis atas saham dapat dilakukan dengan dua metode, yaitu analisis teknikal dan analisis fundamental. Analisis teknikal digunakan untuk memprediksi trend suatu harga saham dengan cara mempelajari data pasar yang lampau, terutama pergerakan harga dan volume. Sedangkan untuk menaksir nilai wajar harga suatu saham perusahaan menggunakan teknik analisis fundamental. Tandelilin (2001) menyebutkan bahwa terdapat dua komponen utama dalam menilai nilai harga wajar saham adalah laba per lembar saham (EPS) dan rasio harga terhadap laba (PER) pada level perusahaan. Analisis ini berdasarkan pada keyakinan bahwa harga saham dipengaruhi oleh kekuatan dari faktor fundamental perusahaan (Sari, 2004).

EPS dapat digunakan untuk menganalisis profitabilitas suatu saham (Hanafi dan Halim, 2000) sementara price earning ratio memberikan informasi mengenai mahal tidaknya harga saham (Salim, 2003). Price earning ratio adalah perbandingan antara tingkat harga saham dengan laba bersih yang didapatkan perusahaan. Pendekatan price earning ratio merupakan pendekatan yang lebih banyak digunakan oleh kalangan analisis saham dan para praktisi. Price earning ratio dapat menjadi indikator pertumbuhan laba dan mengindikasikan pertumbuhan laba di masa yang akan datang. Jika memilih price earning ratio yang rendah maka menunjukan nilai harga pasar yang tinggi atas saham karena semakin murah harga saham tersebut untuk dibeli, semakin baik pula kinerja per lembar saham dalam menghasilkan laba bagi perusahaan. Semakin baik kinerja per lembar saham akan mempengaruhi banyak investor yang datang untuk membeli saham di pasaran tersebut. Sehingga saham tersebut akan dinikmati oleh investor dan pada akhirnya akan menaikkan pula harga sahamnya dan selanjutnya akan berdampak pada perolehan harga saham. Price earning ratio sangat dipengaruhi oleh earning per share (Henry, 2000).

Dengan demikian, seorang investor harus menentukan nilai instrinsik dari suatu aset investasi pada titik waktu tertentu dengan memperhitungkan variabel-variabel yang menentukan nilai, seperti pendapatan saat ini dan mendatang, arus kas, tingkat suku bunga, dan risiko. Menurut Endah (2010) jika terdapat perbedaan harga di bursa dengan estimasi nilai instrinsik dan kecukupan untuk menutup biaya transaksi, tindakan yang pas untuk diambil adalah dengan membeli saham tersebut. Ini terjadi jika secara substansial harga pasar di bawah nilai instrinsik dan menjual apabila diatasnya.

Selain nilai price earning ratio ada juga nilai debt to equity ratio yang sangat berpengaruh terhadap harga saham. Nilai debt to equity ratio merupakan perbandingan antara total utang dengan modal yang digunakan untuk membiayai aset perusahaan. Debt to equity ratio merupakan rasio penting untuk diperhatikan pada saat memeriksa kesehatan 
keuangan perusahaan. Apabila nilai debt to equity ratio meningkat, artinya perusahaan dibiayai oleh kreditor (pemberi hutang) dan bukan dari sumber keuangannya sendiri. Pemberi pinjaman dan investor biasanya memilih debt to equity ratio yang rendah karena kepentingan mereka lebih terlindungi jika terjadi penurunan bisnis pada perusahaan yang bersangkutan, mereka akan cenderung memilih perusahaan dengan keadaan kondisi keuangan perusahaan yang sehat dan tidak banyak dibiayai oleh hutang.

Tentunya, setiap investor atau pemegang saham menginginkan tingkat pengembalian ekuitas yang tinggi tanpa adanya kekhawatiran akan kondisi keuangan perusahaan melalui penilaian return on equity. Pada umumnya, semakin tinggi nilai return on equity akan semakin baik karena menunjukkan bahwa perusahaan menggunakan dana investor dengan baik. Return On Equity merupakan rasio profabilitas yang menunjukkan seberapa besar keuntungan atau laba yang dihasilkan oleh perusahaan setiap satu rupiah yang diinvestasikan para pemegang saham (investor). Rasio ini biasanya dinyatakan dalam persentase (\%). Jadi, return on equity dengan rasio 100\% berarti bahwa setiap 1 rupiah dari ekuitas pemegang saham akan menghasilkan 1 rupiah dari laba bersih. Penelitian dibidang pasar modal telah banyak dilakukan diantaranya tentang faktor-faktor yang mempengaruhi harga saham.

Tujuan penelitian untuk menguji pengaruh price earning ratio, debt to equity ratio dan return on equity terhadap harga saham PT. Mandom Indonesia Tbk Periode 20132017.

\section{LANDASAN TEORI}

\section{Saham}

Saham adalah bentuk penyertaan modal sebuah perusahaan. Perusahaan-perusahaan yang menjual sahamnya kepada masyarakat melalui pasar modal pada umumnya telah berdiri dan menghasilkan laba dalam kurun waktu tertentu. Dengan demikian, diharapkan pada masa yang akan datang laba tersebut bisa tetap dipertahankan atau ditingkatkan sehingga perusahaan dapat memperoleh keuntungan (Joko, 2012).

Menurut Adler dan Lutfi (2009), ada empat jenis nilai saham yaitu, a). Nilai nominal; Nilai nominal adalah harga yang disetorkan ke perusahaan sesuai dengan nilai saham perusahaan tersebut yang ditentukan pada saat penawaran perdana dilakukan. Harga perdana adalah harga yang tertera pada surat saham. Adapun selisih antara harga perdana dan nilai nominal disebut dengan agio saham. b). Nilai buku; Nilai buku adalah nilai suatu perusahaan yang dilihat berdasarkan nilai ekuitas atau total dari modal di dalam neraca perusahaan dibagi jumlah saham yang beredar. c). Nilai pasar; Nilai pasar merupakan harga perdagangan per lembar saham saat ini. Apabila pasar suatu efek sudah tutup maka harga pasar saham adalah harga penutupannya (closing price). Jadi harga pasar inilah yang menyatakan naik-turunnya suatu saham. d). Nilai fundamental; fakta-fakta yang mempengaruhi nilai dasar suatu perusahaan.

Menurut Siamat (2004), harga saham merupakan nilai nominal yang terkandung didalam surat bukti kepemilikan modal bagi suatu perusahaan atau perseroan terbatas. Naik turunnya harga saham tergantung dari perubahan satu atau lebih faktor-faktor yang mempengaruhi harga saham. Pada kondisi perusahaan baik, maka harga saham akan naik dan sebaliknya apabila kondisi perusahaan kurang baik maka harga saham akan cenderung turun. 


\section{Rasio Hutang terhadap Ekuitas (debt to equity ratio)}

Debt to equity ratio merupakan rasio yang digunakan dalam mengukur nilai hutang dengan ekuitas. Rasio ini dihitung dengan cara membandingkan antara seluruh hutang termasuk hutang lancar dengan seluruh ekuitas perusahaan. Menurut Kasmir (2012), Debt to equity ratio berguna untuk mengetahui jumlah dana yang disediakan peminjam (kreditor) dengan pemilik perusahaan. Debt to equity ratio ini sering disebut leverage ratio karena dapat diasumsikan untuk mengukur keberhasilan investasi suatu perusahaan. Debt to equity ratio ini merupakan indikator utama ketika anda ingin mengetahui kesehatan keuangan perusahaan.

Debt to equity ratio dirumuskan sebagai berikut :

$$
\text { Debt to Equity Ratio = } \frac{\text { Total Kewajiban }}{\text { Total Passiva }} \times 100 \%
$$

Meningkatnya nilai debt to equity ratio dalam kurun waktu tertentu menandakan bahwa perusahaan beroperasi dengan ditopang hutang dari kreditor. Padahal sebaiknya perusahaan yang baik itu dapat beroperasi normal, meskipun memanfaatkan sumber keuangannya sendiri. Pemberi pinjaman dan juga Investor di pasar saham umumnya mempertimbangkan saham dengan debt to equity ratio yang rendah. Alasannya tentu agar kepentingannya berinvestasi lebih terlindungi dari potensi tergerusnya keuntungan karena kewajiban yang harus dibayar.

\section{Rasio Harga Laba (price earning ratio)}

Price earning ratio adalah perbandingan harga sebuah saham dengan laba bersih untuk setiap lembar saham perusahaan. Indikator ini telah diaplikasikan dalam laporan keuangan laba rugi dan menjadi bentuk standar pelaporan keuangan perusahaan di Indonesia. Dalam Husnan dan Pudjiastuti (2004) rasio price earning ratio diformulasikan sebagai berikut :

$$
\text { PER }=\frac{\text { Harga Saham }}{\text { Laba per lembar saham }}
$$

Bagi para investor semakin tinggi nilai Price Earning Ratio maka pertumbuhan laba yang diharapkan juga akan mengalami kenaikan. Apabila suatu perusahaan memiliki PER yang tinggi berarti perusahaan tersebut mempunyai tingkat pertumbuhan yang tinggi, sebaliknya perusahaan dengan nilai price earning ratio rendah akan mempunyai tingkat pertumbuhan perusahaan yang rendah.

\section{Rasio Pengembalian Ekuitas (return on equity)}

Return on equity merupakan rasio profitabilitas untuk menilai kemampuan perusahaan dalam menghasilkan laba dari investasi pemegang saham dinyatakan dalam persentase. Berikut ini adalah rumus Return on equity:

$$
\text { ROE }=\frac{\text { Laba bersih }}{\text { Total Ekuitas }} \times 100 \%
$$

Return on equity merupakan salah satu indikator yang digunakan oleh pemegang saham untuk mengukur keberhasilan perusahaan dalam mengelola bisnis yang dijalani. 


\section{METODE PENELITIAN}

Dalam penelitian ini menggunakan metode penelitian dokumentasi, yaitu suatu penelitian yang dilakukan dengan cara mencatat atau mendokumentasikan data yang sudah ada. Pengumpulan data dimulai dengan tahap penelitian pendahulu yaitu dengan mempelajari buku, artikel dan jurnal maupun situs yang berhubungan dengan pokok bahasan dalam penelitian ini, dan dilakukan pengkajian data yang dibutuhkan, ketersediaan data, dan cara memperoleh data. Tahap berikutnya adalah mengumpulkan keseluruhan data yang dibutuhkan guna menjawab persoalan penelitian, memperbanyak literatur untuk menunjang data kuantitatif yang diperoleh. Data dalam penelitian ini menggunakan data sekunder. Satuan analisis dalam penelitian ini adalah emiten sektor kosmetik dan rumah tangga. Data sekunder tersebut diperoleh dari Bursa Efek Indonesia dengan mengakses website www.idx.co.id

\section{HASIL PENELITIAN}

Tabel 1

Pengaruh Price Earning Ratio, Debt to Equity Ratio dan Return On Equity Terhadap Harga Saham PT Mandom Indonesia Tbk Periode 2013-2017

\begin{tabular}{|c|c|c|c|c|}
\hline Variabel & $\mathbf{R}^{2}$ & Konstanta & Koef. Regresi & Sig \\
\hline PER & \multirow{3}{*}{0.511} & & 0.008 & \multirow{3}{*}{0.008} \\
\hline DER & & 9.029 & 0.014 & \\
\hline ROE & & & 0.009 & \\
\hline \multicolumn{5}{|c|}{ Pengujian Sginifikan } \\
\hline \multicolumn{5}{|c|}{ F hitung $5.568>$ F tabel 3.24} \\
\hline \multicolumn{5}{|c|}{ Dependen Variabel: Harga Saham } \\
\hline
\end{tabular}

Berdasarkan Tabel 1, menunjukkan bahwa nilai $\mathrm{F}$ hitung sebesar 5.568 dengan nilai sig. $=0,008$. Nilai $F_{\text {hitung }} 5.568>F_{\text {tabel }} 3.24$ dan nilai sig. lebih kecil daripada 0,05 atau nilai $0,008<0,05$ maka Ho ditolak dan Ha diterima, artinya terdapat pengaruh positif dan signifikan price earning ratio, debt to equity ratio dan return on equity terhadap harga saham PT Mandom Indonesia Tbk periode 2013-2017.

Nilai koefisien determinasi sebesar 0.511 atau $51,1 \%$, artinya $51,1 \%$ variabel harga saham dapat dijelaskan oleh variabel price earning ratio, debt to equity ratio dan return on equity, sedangkan sisanya sebesar $48,9 \%$ disumbangkan oleh variabel lain yang tidak diteliti.

Persamaan regresi berganda $: \mathrm{Y}=9.029+0.008 \mathrm{X}_{1}+0.014 \mathrm{X}_{2}+0.009 \mathrm{X}_{3}$

Nilai koefisien regresi price earning ratio sebesar 0.008 , artinya jika price earning ratio mengalami kenaikan sebesar $1 \%$ maka akan menaikkan harga saham sebesar $0.008 \%$ dengan asumsi variabel bebas yang lain bernilai tetap. Nilai koefisien regresi debt to equity ratio positif sebesar 0.014, artinya jika debt to equity ratio mengalami kenaikan sebesar $1 \%$ maka akan menaikkan harga saham sebesar 0.014 dengan asumsi variabel bebas yang lain bernilai tetap. Nilai koefisien regresi return on equity positif sebesar 0.009 artinya jika return on equity mengalami kenaikan sebesar $1 \%$ maka akan menaikkan harga saham sebesar $0.009 \%$ dengan asumsi variabel bebas yang lain bernilai tetap. 
Tabel 2

Pengaruh Price Earning Ratio Terhadap Harga Saham

PT Mandom Indonesia Tbk Periode 2013-2017

\begin{tabular}{ccccc}
\hline Variabel & \multicolumn{1}{c}{$\mathbf{R}^{\mathbf{2}}$} & Konstanta & Koef. Regresi & Sig \\
\hline PER & 0.031 & 9.534 & 0.007 & 0.456 \\
\hline Pengujian Sginifikan & & & \\
\hline t hitung 0.762 < t tabel 2.120 & & & \\
\hline &
\end{tabular}

Berdasarkan Tabel 2, menunjukkan bahwa nilai thitung $0,762<t_{\text {tabel }} 2.120$ dan untuk nilai signifikan sebesar 0,456 . Nilai signifikan lebih besar dari nilai 0,05 atau nilai $0,456<$ 0,05, maka dapat disimpulkan Ha ditolak dan Ho diterima, artinya price earning ratio tidak berpengaruh terhadap harga saham PT Mandom Indonesia Tbk periode 2013-2017.

Nilai koefisien determinasi sebesar 0.031 atau 3,1\%, artinya 3,1\% variabel harga saham dapat dijelaskan oleh variabel price earning ratio, sedangkan sisanya sebesar $96,9 \%$ disumbangkan oleh variabel lain yang tidak diteliti.

Persamaan regresi linear sederhana : $\mathrm{Y}=9.534+0.007 \mathrm{X}_{1}$

Nilai konstanta sebesar 9.534, artinya jika price earning ratio nilainya sama dengan nol, maka harga saham nilainya sudah tearbentuk sebesar 9.534. Nilai koefisien regresi price earning ratio positif sebesar 0.007 , artinya jika price earning ratio mengalami kenaikan sebesar $1 \%$ maka akan menaikkan harga saham sebesar $0.007 \%$, dengan asumsi variabel bebas yang lain tetap.

Tabel 3

Pengaruh Debt to Equity Ratio Terhadap Harga Saham PT Mandom Indonesia Tbk Periode 2013-2017

\begin{tabular}{ccccc}
\hline Variabel & \multicolumn{1}{c}{$\mathbf{R}^{\mathbf{2}}$} & Konstanta & Koef. Regresi & Sig \\
\hline DER & 0.635 & 9.267 & 0.014 & 0.003 \\
\hline Pengujian Sginifikan & & & \\
\hline t hitung 3.489 $>$ t tabel 2.120 & & & \\
\hline
\end{tabular}

Sumber : diolah 2018

Berdasarkan Tabel 3, menunjukkan bahwa nilai $t_{\text {hitung }} 3.499>t_{\text {tabel }} 2.120$ dan untuk nilai signifikan sebesar 0,03 . Nilai signifikan lebih kecil dari nilai 0,05 atau nilai 0,003 > 0,05, maka dapat disimpulkan Ha diterima dan Ho ditolak, artinya debt to equity ratio memiliki pengaruh positif dan signifikan terhadap harga saham PT. Mandom Indonesia Tbk Periode 2013-2017.

Nilai koefisien determinasi sebesar 0.403 atau 40,3\%, artinya 40,3\% variabel harga saham dapat dijelaskan oleh variabel debt to equity ratio, sedangkan sisanya sebesar $59,7 \%$ disumbangkan oleh variabel lain yang tidak diteliti.

Persamaan regresi linear sederhana adalah : $\mathrm{Y}=9.267+0.014 \mathrm{X}_{2}$

Nilai koefisien regresi debt to equity ratio positif sebesar 0.014 , artinya jika debt to equity ratio mengalami kenaikan sebesar $1 \%$, maka akan menaikkan harga saham sebesar $0.014 \%$. 


\section{Tabel 4}

Pengaruh Return On Equity Ratio Terhadap Harga Saham PT Mandom Indonesia Tbk Periode 2013-2017

\begin{tabular}{ccccc}
\hline Variabel & \multicolumn{1}{c}{$\mathbf{R}^{\mathbf{2}}$} & Konstanta & Koef. Regresi & Sig \\
\hline ROE & 0.146 & 9.596 & 0.003 & 0.539 \\
\hline Pengujian Sginifikan & & & \\
\hline t hitung 0.626 < t tabel 2.120 & & & \\
\hline &
\end{tabular}

Berdasarkan Tabel 4, menunjukkan bahwa nilai thitung $0.626<t_{\text {tabel }} 2.120$ dan untuk nilai signifikan sebesar 0,539 . Nilai signifikan lebih besar dari nilai 0,05 atau nilai $0,539<$ 0,05, maka dapat disimpulkan Ha ditolak dan Ho diterima, artinya return on equity ratio tidak berpengaruh terhadap harga saham PT. Mandom Indonesia Tbk Periode 2013-2017.

Nilai koefisien determinasi sebesar 0.021 atau $2,1 \%$, artinya $2,1 \%$ variabel harga saham dapat dijelaskan oleh variabel return on equity ratio, sedangkan sisanya sebesar 97,9\% disumbangkan oleh variabel lain yang tidak diteliti.

Persamaan regresi linear sederhana adalah : $\mathrm{Y}=9.596+0.003 \mathrm{X}_{3}$

Nilai koefisien regresi return on equity ratio positif sebesar 0.003 , artinya jika return on equity ratio mengalami kenaikan sebesar $1 \%$, maka akan menaikkan harga saham PT. Mandom Indonesia Tbk Periode 2013-2017 sebesar 0.003\%.

\section{KESIMPULAN DAN SARAN}

\section{Kesimpulan}

Dari hasil analisis dan pembahasan, maka dapat ditarik kesimpulan sebagai berikut : 1). Price earning ratio, debt to equity ratio dan return on equity memiliki pengaruh positif dan signifikan terhadap harga saham PT Mandom Indonesia Tbk periode 2013-2017. 2). Price earning ratio memilki pengaruh posotif namun tidak signifikan terhadap harga saham. PT Mandom Indonesia Tbk periode 2013-2017. 3). Debt to equity ratio memiliki pengaruh positif dan signifikan terhadap harga saham PT Mandom Indonesia Tbk periode 2013-2017. 4). Return on equity memiliki pengaruh positif namun tidak signifikan terhadap harga saham PT Mandom Indonesia Tbk periode 2013-2017.

\section{Saran}

Dari hasil yang diperoleh pengaruh Price earning ratio, debt to equity ratio dan return on equity terhadap harga saham, maka penulis mencoba untuk memberikan saran sebagai bahan untuk rekomendasi sebagai berikut : 1). Bagi para investor sebelum memutuskan untuk menanamkan investasinya pada suatu perusahaan, disarankan agar mempertimbangkan berbagai macam faktor yang dapat mempengaruhi harga saham. Investor sebaiknya tidak hanya mempertimbangkan dari sisi laba perusahaannya saja, tetapi ada faktor-faktor yang lain, seperti Price earning ratio, debt to equity ratio dan return on equity. 2). Bagi perusahaan disarankan untuk lebih memperhatikan pencapaian kinerja keuangan khususnya pada profitabilitas dan nilai pasar dalam menghasilkan keuntungan (laba) agar menarik minat investor untuk menanamkan investasinya. 3). Bagi penelitian selanjutnya disarankan untuk memperluas lagi sampel penelitian dan menambah periode waktu penelitian, serta menambah rasio lain yang diduga memiliki pengaruh terhadap harga saham. 


\section{DAFTAR PUSTAKA}

Nicky Hogan, 2017, Yuk Nabung Saham: Selamat Datang, Investor Indonesia!, Jakarta : Elex Media Komputindo

Iswi Hariyani dan R. Serfianto D.P, 2010, Buku Pintar Hukum Bisnis Pasar Modal : Strategi Tepat Investasi Saham, Obligasi, Waran, Right, Opsi, Reksadana \& Produk Pasar Modal Syariah, Jakarta : Visimedia

Ir.Kuswadi, MBA, 2008, Memahami Rasio-Rasio Keuangan bagi Orang Awam, Cetakan ke-2, Jakarta : Elex Media Komputindo

Kho Sin Hien \& Fransiska Ida Mariani, 2017, Financial Management Canvas, Jakarta : Elex Media Komputindo

Halim, Abdul dan Mamduh M. Hanafi, 2009, Analisis Laporan Keuangan Edisi 4, Yogyakarta : UPP STIM YKPN.

Christina Widhya Utami, 2010, Manajemen Ritel : Strategi dan implementasi operasional bisnis ritel modern di Indonesia, Jakarta: SalembaEmpat

Eduardus Tandelilin, 2001, Analisis Investasi dan Manajemen Portofolio, Edisi Pertama, Yogyakarta : BPFE

Sari, W., 2004, Hubungan antara Volatilitas Perdagangan dan Volatilitas Harga Intraday Di Bursa Efek Jakarta, Tesis Magister Sains Sekolah Pascasarjana Universitas Gadjah Mada Yogyakarta (tidak dipublikasikan).

Hanafi, M. dan A.Halim, 2000, Analisis Laporan Keuangan, Edisi 1, Cetakan 2, Yogyakarta : Unit Penerbitan dan Percetakan AMP-YKPN.

Salim, Lani, 2003,Analisa Teknikal dalam Perdagangan Saham, Edisi Pertama, Jakarta : Elex Media Komputindo.

Henry Simamora, 2000, Basis Pengambilan Keputusan Bisnis, Jakarta : Salemba Empat

Endah Tri Utami, 2010, Cara Cerdas Berinvestasi: via Online Trading, Jakarta : TransMedia Pustaka

Zulfikar, 2016, Pengantar Pasar Modal dengan Pendekatan Statistika, Edisi Satu Cetakan Satu, Yogyakarta : Deepublish

Iswi Hariyani dan R. Serfianto D.P, 2010, Buku Pintar Hukum Bisnis Pasar Modal : Strategi Tepat Investasi Saham, Obligasi, Waran, Right, Opsi, Reksadana \& Produk Pasar Modal Syariah, Jakarta : Visimedia

Eeng Ahman dan Epi Indriani, 2007, Membina Kompetensi Ekonomi untuk SMA/MA Kelas XI Program Ilmu Pengetahuan Sosial, Jilid 2 Edisi 1 Cetakan 1, Bandung : Grafindo Media Pratama

Joko Salim, S.Kom, SE. CFP, 2012, Jangan Coba-coba Main Saham Sebelum Baca Buku Ini, Jakarta : VisiMedia

Prof. Dr. Adler H. Manurung, R.F.C \& Lutfi T. Rizky, S.E., M.M., R.F.A, 2009, Successful Financial Planner: A Complete Guide, Jakarta : Grasindo

Siamat, Dahlan, 2004, Manajemen Lembaga Keuangan, Edisi Keempat, Jakarta : Lembaga Penerbit Fakultas Ekonomi Universitas Indonesia.

Haruman, Tendi, dkk, 2005,Pengaruh Faktor Fundamental dan Risiko Sistematis terhadap Tingkat Pengembalian Saham BEJ, Jurnal Usahawan, No.11, November, pp 26-37.

Alwi, I.Z, 2003, Pasar Modal, Teori dan Aplikasi Cetakan Pertama, Jakarta : Yayasan Pancur Siwah

Kariyoto, 2017, Analisis Laporan Keuangan, Malang : UniversitasBrawijaya Press.

Kasmir, 2016, Analisis Laporan Keuangan, Jakarta : Raja Grafindo Persada.

Susan Irawati, 2005, Manajemen Keuangan, Bandung : Penerbit Pustaka 
Rahardjo, Budi, 2007, Keuangan dan Akuntansi, Edisi Pertama, Cetakan Pertama, Yogyakarta : Graha Ilmu

Kasmir, 2008,Bank dan Lembaga Keuangan Lainnya. Edisi Revisi 2008, Jakarta: PT. RAJAGRAFINDO PERSADA

Sofyan Syafri Harahap, 2008, Analisis Kritis Atas Laporan Keuangan, Jakarta : Raja Grafindo Persada.

Kasmir, 2016,Analisis Laporan Keuangan, Jakarta: Raja Grafindo Persada.

Agus Sartono, 2010, Manajemen Keuangan Teori dan Aplikasi Edisi 4, Yogyakarta : BPFE

Kasmir, 2012, Analisis Laporan Keuangan, Jakarta : PT. Raja Grafindo Persada.

Hanafi, 2004, Manajemen Keuangan, Yogyakarta: BPFE UGM.

Tjipto Darmadji dan Hendry M. Fakhruddin, 2001,Pasar Modal di Indonesia. Jakarta :Salemba Empat.

Husnan, Suad., Enny Pudjiastuti, 2004,Dasar-Dasar Manajemen KeuanganEdisi Keempat, Yogyakarta : UPP AMP YKPN.

Arief Sugiono, 2009, Manajemen Keuangan, Jakarta: Penerbit PT. Gramedia Widiasarana Indonesia.

Sekaran, Uma, 2003, Research Methods For Business: A Skill Building Aproach, New York-USA: John Wiley and Sons, Inc

J. Moleong, Lexy, 2000, Metode Penelitian Kualitatif, Bandung : Remaja Rosdakary.

Ghozali, Imam, 2016,Aplikasi Analisis Multivariete Dengan Program IBM SPSS 23 (Edisi 8). Cetakan ke VIII. Semarang : Badan Penerbit Universitas Diponegoro.

Ghozali, Imam, 2005, Aplikasi Analisis Multivariate dengan SPSS, Semarang : Badan Penerbit UNDIP.

Sihombing, Gregorius, 2008, Kaya dan Pinter Jadi Trader \& Investor Saham, Yogyakarta :Penerbit Indonesia Cerdas.

Haruman, Tendi, dkk, 2005,Pengaruh Faktor Fundamental dan Risiko Sistematis terhadap Tingkat Pengembalian Saham BEJ, Jurnal Usahawan, No.11, November, pp 26-37.

Hanafi, Mamduh M, dan Abdul Halim, 2012, Analisis Laporan Keuangan, Edisi Keempat. Yogyakarta: UPP STIM YKPN.

Fahmi, Irham, 2012,Analisis Kinerja Keuangan. Bandung : Alfabeta.

Agus Sartono, 2008, Manajemen keuangan teori, dan aplikasi. Yogyakarta: BPFE Yogyakarta. 